\title{
A Delegacia da Mulher perante as normas e leis para 0 enfrentamento da violência contra a mulher: um estudo de caso $^{1}$
}

\author{
Lídio de Souza \\ Universidade Federal do Espírito Santo \\ Mirian Beccheri Cortez \\ Universidade Federal do Espírito Santo
}

\begin{abstract}
Este estudo analisa o funcionamento de uma Delegacia Especializada no Atendimento à Mulher (Deam) na cidade de Vitória (ES), considerando sua equipe de funcionários e infraestrutura. Os dados foram obtidos por meio de observações de campo e entrevistas individuais com os 14 funcionários da delegacia, analisados com base na "Norma Técnica de Padronização das Deams" e nas informações do relatório "Observe - Sobre as condições para aplicação da Lei no 11.340/2006 (Lei Maria da Penha) nas Deams". Houve coesão entre as respostas dos participantes, que destacaram: prejuízo em suas atividades decorrente da falta de funcionários; bom relacionamento entre os membros da equipe; e demanda por treinamento dos profissionais e por equipe psicossocial na Deam. Sobre a delegacia, foram feitas críticas à precariedade da estrutura física do prédio e dos equipamentos (viaturas, computadores), bem como à falta de apoio da Polícia Civil à Deam. Destaca-se a necessidade de investimentos na infraestrutura, na ampliação e qualificação da equipe, bem como na concretização da tríade prevenção/assistência/ repressão, usualmente ignorada pelo Estado e órgãos responsáveis.
\end{abstract}

Palavras-chave: delegacia; Deam; violência contra a mulher; Lei Maria da Penha.

La realidad de una comisaria de mujer según las normas e leyes para el enfrentamiento de la violencia contra la mujer

Este estudio examina el funcionamiento de una Comisaria Especializada de Atención a la Mujer (Deam) en la ciudad de Vitória (ES), teniendo en cuenta su personal e infraestructura. Los datos provienen de las observaciones de campo y entrevistas con 14 funcionarios de la comisaría. Se los analizamos con base en las propuestas de la Norma técnica de normalización de las Comisarias Especializadas y en las informaciones del relatorio Observe — sobre las condiciones para aplicación de la Ley 11.340/2006 (Ley Maria da Penha) en las Deams. Hubo cohesión entre las respuestas de los participantes, que des-

DOI: http://dx.doi.org/10.1590/0034-76121141

Artigo recebido em 3 maio 2012 e aceito em 13 fev. 2014.

${ }^{1}$ Apoio financeiro: Coordenação de Aperfeiçoamento de Pessoal de Nível Superior (Capes). 
tacaron: el perjuicio de sus actividades debido a la carencia de personal; las buenas relaciones del equipo; la demanda de formación de los profesionales y de una equipo psicosocial en Deam. Acerca de la Deam, se criticó a la precariedad de la estructura física del edificio y de los materiales (coches y ordenadores), así como la falta de apoyo de la Policía Civil a comisaría de policía especializada. Se enfatiza la necesitad de inversión en infraestructura, ampliación y cualificación profesional, bien como la concretización de la tríada prevención-asistencia-represión, en general ignorada por el Estado y por los organismos responsables.

Palabras clave: comisaria; Deam; violencia contra la mujer; Ley Maria da Penha.

Women's Defense Police Station towards the rules and laws for combating violence against women: a case study

This study analyzes the operation of a Specialized Police Station for Women (DEAM) in the city of Vitória, Espírito Santo, Brazil, considering its staff and infrastructure. Data were obtained through field observations and individual interviews with the 14 employees at the police station, analyzed on the basis of the proposals of the "Technical Guidelines for the Standardization of DEAMs" and according to information from the report "Observe - On the conditions for applying the Law 11,340/2006 (Maria da Penha Law) at DEAMs". There was cohesion between the participants' answers, who highlighted: loss in their activities due to lack of staff; good relationship between team members; and demand for training of professionals and for psychosocial staff at DEAM. Regarding the police station, remarks were made to the precarious physical structure of the building and equipment (police cars, computers), as well as to the lack of support from the Civil Police to DEAM. We stress the importance to invest in infrastructure, in staff increase and training, as well as in deploying the triad prevention/assistance/ repression, usually ignored by the State and responsible agencies.

Keywords: police officer; Deam; violence against women; Maria da Penha Law.

\section{Introdução}

O enfoque da violência contra mulheres como um problema social e, posteriormente, também de saúde pública abre espaço para demandas por ações públicas tanto no âmbito da segurança quanto do direito e da saúde (Vilella e Lago, 2007; Lamoglia e Minayo, 2009; Arruda da Silva et al., 2012). Assim, para compreendermos a atual configuração da rede de enfrentamento à violência, e a ênfase dada à criminalização desse fenômeno como forma de enfrentá-lo, é relevante a contextualização sociopolítica de criação das delegacias especializadas e também de outros mecanismos criados pelo governo com o objetivo de punir e coibir a violência contra a mulher.

Ao analisar a relação entre as lutas feministas e as políticas públicas de enfrentamento à violência contra mulheres no Brasil, Santos (2008) distingue três momentos-chave: 1) a implantação da primeira delegacia da mulher em São Paulo, em 1985; 2) o surgimento dos Juizados Criminais Especiais (Jecrims), a partir de 1995; e 3) a promulgação, em 2006, da Lei no 11.340, Lei Maria da Penha. A autora analisa esses três momentos como marcos do caminho percorrido pelos movimentos feministas, juntamente com o Estado, para o combate 
à violência doméstica e familiar e discute o impacto das demandas feministas e das oportunidades políticas no direcionamento das agendas governamentais.

As Delegacias Especializadas de Atendimento às Mulheres (Deams) são um marco na luta feminista: elas materializam o reconhecimento da violência contra mulheres como um crime e implicam a responsabilização do Estado no que se refere à implantação de políticas que permitam o combate a esse fenômeno.

O processo de implantação das Deams teve início com a mobilização feminista dos anos 1970-80 (Arruda da Silva et al., 2012). Na pauta do movimento brasileiro, a luta pelo reconhecimento da violência doméstica como uma das principais violências que atingem a mulher tornou-se prioridade. Relevante enfatizar que, nesse período, crimes e decisões jurídicas envolvendo homens e mulheres de destaque na mídia deram maior visibilidade às ocorrências de violência conjugal contra a mulher. Quando levados a julgamento, os autores da violência eram costumeiramente defendidos com base no sofrimento causado pela rejeição da mulher amada e no princípio de "legítima defesa da honra"2 (Blay, 2003; Machado, 2002; Pasinato e Santos, 2008).

Como descreve Blay (2003:88), o movimento em defesa da vida das mulheres e pela punição de seus assassinos alcançou "seu auge após 30 de dezembro de 1976, quando Angela Diniz foi morta por Doca Street, de quem ela desejava se separar". Doca foi inocentado no primeiro julgamento ("matei por amor", foi sua declaração para a imprensa), mas condenado no segundo. Esse episódio especificamente tornou-se alvo de grande debate público e gerou diversas manifestações de grupos feministas, sob o lema: "Quem ama não mata". ${ }^{3}$ Outro caso de grande repercussão foi o assassinato de Eliane de Grammont por seu ex-marido, o cantor Lindomar Castilho, em março de 1981, quase um ano após a separação do casal. Preso, Lindomar afirmou que cometeu o crime por motivo passional e por legítima defesa da honra. Foi condenado a 12 anos de reclusão, cumpriu quatro e saiu em liberdade condicional por bom comportamento.

Nesse contexto de denúncias e reivindicações, grupos feministas passam a organizar serviços, os chamados SOS Mulher, para acolher e orientar as mulheres que sofriam violência. Em agosto de 1985, a primeira Delegacia de Defesa da Mulher (DDM) do Brasil seria, então, inaugurada na cidade de São Paulo.

No ano de 1995, com base nos princípios da celeridade, simplicidade, informalidade e economia (Lei no 9.099/1995), foram criados os Jecrims, encarregados dos casos de "infra-

\footnotetext{
${ }^{2}$ Mais recentemente, Rocha (2007) citou alguns estudos que identificaram o uso da legítima defesa da honra em julgamentos ocorridos entre 1998 e 2003, revelando que esse argumento permanece sendo utilizado, ainda que mais questionado.

${ }^{3}$ A repercussão deste caso foi tanta que, em 1982, uma minissérie cujo título reproduzia este lema ("Quem ama não mata") foi produzida e transmitida pela Rede Globo de Televisão. Inspirada nos crimes passionais que mobilizavam a opinião pública na época, a minissérie abordou "o relacionamento amoroso na classe média através da história de cinco casais, cada um com uma visão particular sobre casamento, amor e fidelidade". Segundo o diretor, Daniel Filho, algumas histórias da minissérie foram baseadas nas experiências pessoais dele e dos autores da trama. (Informações disponíveis no site: <http://minisserie.blogspot.com/2010/03/quem-ama-nao-mata.html>)
} 
ções penais de menor potencial ofensivo", cuja penalidade prevista é menor que um ano de detenção. Incluíam-se, portanto, os casos de lesão corporal leve e ameaça, os delitos mais recorrentes de violência doméstica e familiar registrados nas Deams e, logo, também os mais frequentes nos Jecrims (Cortez, 2006; Santos, 2008). Com isso, essas delegacias passaram a gerar Termos Circunstanciados, documentos que substituíram o Boletim de Ocorrência (BO) e que, com o laudo e o resumo da ocorrência, eram diretamente encaminhados ao Jecrim "para realização de audiência de conciliação e julgamento", sem necessidade de investigação prévia do caso e instauração de inquérito (Santos, 2008:17).

Apesar de esta decisão ter, de fato, agilizado a chegada dos casos à instância jurídica, Santos (2008, 2010) e Oliveira (2008) discutem que, ao ser enquadrada na Lei no 9.099/1995, a violência contra a mulher tornou-se um problema a ser mediado e não mais investigado e julgado e a conciliação entre os envolvidos destacou-se como o principal objetivo do Jecrim. Por essa razão, as críticas a esse modelo surgiram rapidamente e se dirigiam tanto ao pouco conhecimento dos conciliadores e juízes sobre a temática da violência familiar/doméstica e questões de gênero, quanto à consequente banalização e descriminalização da violência doméstica/familiar. O elevado número de desistências do processo criminal durante as audiências de conciliação indicava, segundo muitos estudiosos, a despolitização da questão da violência, uma vez que, novamente, ela passava a ser negociada em âmbito privado (Oliveira, 2008).

Ao longo dos anos 1990, já com os Jecrims em atividade, os movimentos feministas permaneciam ativos na luta por leis específicas sobre a violência contra a mulher (Santos, 2008). Nessa década, diversos encontros de âmbito nacional e internacional ocorreram com a finalidade de se reconhecer a violência contra a mulher como uma violação dos direitos humanos e como um grave problema de saúde pública. Entre os documentos resultantes dessa mobilização está a Convenção para a Eliminação, Prevenção, Punição e Erradicação da Violência contra a Mulher, também conhecida como Convenção de Belém do Pará, aprovada pela assembleia da ONU em 1994 e ratificada pelo Brasil em 1995 (Agende, 2004).

Nesse contexto, em 2001 a Comissão Interamericana de Direitos Humanos condenou o Estado brasileiro por violar direitos e deveres previstos na Convenção de Belém do Pará no caso de Maria da Penha Maia Fernandes (dupla tentativa de homicídio da mulher pelo marido). O Estado se vê, então, obrigado a intensificar as medidas para combater a violência contra a mulher, processo esse que tem como resultado mais marcante a criação da Lei $\mathrm{n}^{\circ}$ 11.340/2006, chamada Lei Maria da Penha. A lei, sancionada em 7 de agosto de 2006, entrou em vigor em 22 de setembro desse mesmo ano (Guimarães et al., 2011) e retirou dos Jecrims a competência para julgar os casos de violência contra a mulher, alterando, novamente, os procedimentos para encaminhamento das denúncias pela Deam, que passaram a ser registradas em BOs. A Deam voltou a instaurar inquéritos, investigar a denúncia e encaminhar o pedido de abertura dos processos à Vara Criminal responsável, entre outras funções.

A promulgação da Lei Maria da Penha gerou diversos debates sobre sua constitucionalidade, uma vez que, para alguns, ao enfocar os direitos das mulheres, ela feriria o princípio da isonomia, excluindo homens que também sofrem com a violência doméstica, praticada por 
parceiras ou familiares (Alencar e Melo, 2011; Nunes e Hita, 2010). Para resolver tal impasse, em dezembro de 2007, o presidente Luiz Inácio Lula da Silva ajuizou uma Ação Declaratória de Constitucionalidade e, em fevereiro de 2012, o Superior Tribunal Federal (STF) referendou por unanimidade a validade da lei, reduzindo, mas não eliminando totalmente, críticas a respeito da mesma. Segundo as leis brasileiras, os casos de violência conjugal contra homens devem ser amparados na Lei no 9.099/1995 e encaminhados para o Jecrim.

Afora tais pontos, muito pertinentes e merecedores de reflexões que permitam alcançar, de fato, relações igualitárias também nos princípios da Lei, valorizamos o fato de a Lei Maria da Penha favorecer a publicização das violências cometidas contra as mulheres, ao mesmo tempo que reforça a necessidade de prevenção desses atos, por meio de campanhas educativas, bem como de assistência a todos os envolvidos no conflito (mulheres, crianças e também os homens).

A criação da Lei Maria da Penha tornou-se um dos marcos mais importantes dos movimentos de enfrentamento à violência contra a mulher ao estabelecer medidas para a proteção e assistência da mulher, bem como "punição e possibilidade de reeducação dos agressores" (Ministério da Justiça, 2010:16). Segundo as especificações da lei, a violência contra a mulher deve ser combatida por meio da tríade prevenção-assistência-repressão.

De acordo com a Norma técnica de padronização das Deams, a Deam deveria assumir uma posição de órgão preventivo-repressor, atendendo aos seguintes desafios: 1) Profissionalização (de todo o grupo gestor e operacional), 2) Prevenção (abarcar o sentido final de prevenir o delito, "seja por dissuasão, eficiência e eficácia do método investigativo, seja pelo papel proativo de interlocução"), 3) Educação e cidadania ("especialmente pela correta audição do público atendido") e 4) Investigação (ação investigativa em que polícia civil, militar e outros órgãos e serviços responsáveis mantenham relações "de solidariedade ética e técnica", favorecendo o ciclo de ações do sistema) (Ministério da Justiça, 2010:28-29).

As delegacias especializadas são parte da Polícia Civil, estão vinculadas às secretarias estaduais de Segurança Pública e integram, atualmente, a "Política nacional de prevenção, enfrentamento e erradicação da violência contra a mulher" (Ministério da Justiça, 2010:27). Após a criação da primeira delegacia em São Paulo, ainda no ano de 1985, outras seis delegacias foram instaladas, nas seguintes capitais: Belo Horizonte (MG), Cuiabá (MT), Curitiba (PR), Florianópolis (SC), Recife (PE) e Vitória (ES). Em São Paulo esta delegacia se firmou com a denominação Delegacia de Defesa da Mulher (DDM), mas, ainda que alguns estados utilizem variações dessa nomenclatura, há certo consenso em torno da designação utilizada na Norma Técnica publicada em 2010 (Ministério da Justiça, 2010).

Atualmente, todas as capitais brasileiras contam com ao menos uma Deam e, segundo o relatório Observe sobre as condições para aplicação da Lei 11.340/2006 (Lei Maria da Penha) nas Deams (Observe, 2010), em 2009 foram contabilizadas 475 delegacias especializadas, em todo o Brasil, a maior parte delas concentrada na região Sudeste, mais especificamente no estado de São Paulo.

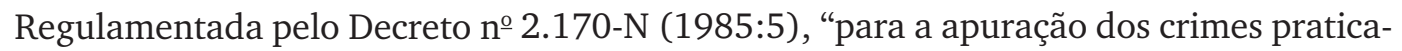
dos contra pessoas do sexo feminino", a delegacia especializada de Vitória tinha como âmbito 
inicial de ação toda a região da Grande Vitória (na época, Vitória, Vila Velha, Cariacica, Serra e Viana). Em nossas observações e estudo de documentos, constatamos que a delegacia e seus serviços, desde então, têm sido adaptados às alterações nas leis e às necessidades de suas usuárias e da Polícia Civil. Por exemplo, atualmente essa Deam registra apenas denúncias de mulheres residentes no próprio município e encaminha as denúncias de violência contra crianças e adolescentes para a Delegacia Especializada de Proteção à Criança e ao Adolescente.

Duas alterações mais recentes no funcionamento dessa Deam (primeiro semestre de 2011) referem-se aos casos de violência contra idosas (acima de 60 anos de idade), que passaram a ser registrados na Delegacia Especializada para o Idoso, e às denúncias de injúria, calúnia e difamação (chamados crimes contra a honra), atualmente de responsabilidade do Núcleo Especializado de Promoção e Defesa dos Direitos da Mulher (Nudem), que confecciona o Termo Circunstanciado e encaminha os casos ao Jecrim.

Diversos estudos, entre os quais o de Pasinato (2010), indicam que o número de BOs registrados nas delegacias aumenta a cada ano. Em Vitória, o indicativo dos efeitos dessa lei sobre os registros poderia ser aferido comparando-se a quantidade de boletins registrados na Deam em períodos anterior e posterior à promulgação da Lei. O relatório técnico do Instituto Jones dos Santos Neves (2008) indica que, nos anos de 2005 e 2006, foram registradas, respectivamente, 1.356 e 1.173 ocorrências. Como é analisado no próprio relatório, a partir da implementação da Lei no 11.340/2006, a Deam passou a priorizar o atendimento de casos de violência doméstica e familiar, o que implicou o encaminhamento dos outros casos para a Delegacia de Polícia Judicial ou delegacias especializadas e, consequentemente, a queda do número de registros na Deam. Ainda, com a entrada da Lei em vigor pode-se inferir certa retração do número de denúncias ou do número de ocorrências, durante curto período de tempo, devido a dúvidas e desconfianças em relação à nova lei.

Dados mais atuais, fornecidos pela própria Deam, indicaram o registro de cerca de 2.000 boletins de ocorrência no ano de 2009 e 1.669 BOs em 2010. Acreditamos que a queda de um ano para o outro pode ser decorrente de alterações nos serviços da Deam, como as descritas anteriormente, ou ainda ao menor número de denúncias ou de ocorrências.

Se as delegacias especializadas são espaços de referência para as mulheres em situação de violência, entendemos que se faz relevante não apenas o acompanhamento das ocorrências nelas registradas, mas também o conhecimento de suas instalações, sua equipe e seu funcionamento. O projeto Construção e Implementação do Observatório da Lei 11.340/2006 — Lei Maria da Penha — foi desenvolvido no período de 2007 a 2010 e propõe fornecer indicadores que sirvam como base para a construção "de novos parâmetros de ação", bem como para o planejamento de capacitações e para o desenvolvimento "de instrumentos de monitoramento e avaliação das políticas de enfrentamento da violência contra a mulher" (Observe, 2010:8).

O relatório resultante deste projeto apresenta e discute o monitoramento de Deams e Juizados de Violência Doméstica e Familiar nas capitais brasileiras e Distrito Federal (Observe, 2010). Os dados publicados são os mais atuais no momento e permitem uma visão geral (mas, ainda assim, restrita) da situação desses órgãos (equipes, estrutura, funcionamento, deficiências e ações) nas capitais. Infelizmente, segundo o relatório, em decorrência de "razões 
adversas" (Observe, 2010:13, nota de rodapé), a Deam de Vitória não foi incluída na pesquisa — assim como a delegacia especializada de Rio Branco (AC). A ausência de dados sobre a Deam em questão provocou a realização do presente estudo, cujos dados podem se somar ao conjunto de informações sobre as Deams brasileiras e ser relevantes para o cotejamento com as informações das delegacias especializadas em funcionamento no país.

\section{Objetivo}

Este estudo teve o propósito de descrever e analisar o funcionamento da Deam, no que tange à equipe de funcionários (quadro de pessoal, dinâmica de trabalho do grupo) e sua infraestrutura (localização, estrutura física, equipamentos e contatos com serviços de apoio).

Tais aspectos são analisados e discutidos tomando-se como referência a Norma técnica de padronização das Deams (Ministério da Justiça, 2010) e as informações sobre outras Deams referidas no relatório sobre Deams e juizados supracitados (Observe, 2010).

\section{Método}

A presente pesquisa, de caráter qualitativo, foi desenvolvida com base em dados recolhidos por meio de entrevistas com os funcionários da Deam e por meio da análise dos registros realizados ao longo de períodos de observação ocorridos na própria delegacia. Desse modo, a pesquisa caracteriza-se por ser um estudo de caso (Gil, 2009), uma vez que se propõe a conhecer e analisar aspectos específicos de uma instituição (Deam-Vitória), escrevendo seu contexto e situações reais de funcionamento.

\subsection{Participantes}

Participaram da pesquisa todos os 14 funcionários que atuavam na Deam no primeiro semestre de 2011. Desses, 12 eram efetivos, uma das digitadoras era estagiária e a auxiliar de serviços gerais era terceirizada. Dos 14 participantes, três eram homens, todos investigadores.

\subsection{Procedimentos}

\section{Entrevistas}

A coleta de dados foi realizada por meio da aplicação de um roteiro de entrevista composto por três partes: 1. Caracterização dos participantes (sexo, idade, escolaridade, tempo de serviço na Polícia Civil e na Deam), 2. Questões sobre as ocorrências de violência contra a mulher 
(caracterização da usuária, casos mais e menos atendidos, motivação do registro da denúncia) e 3. Breve avaliação da Deam — pontos positivos e negativos e avaliação sobre aspectos a serem melhorados.

A primeira proposta para coleta dos dados valia-se da utilização de questionários autoaplicáveis, mas ao retornar à Deam para recolher o material depois do período combinado de duas semanas, nenhum questionário havia sido respondido. Após sugestão de uma das policiais, optamos por aplicá-los individualmente, na forma de entrevista. A aplicação dos roteiros teve duração de 20 a 40 minutos e ocorreu na própria Deam (na cozinha ou em sala disponível), no horário de trabalho dos profissionais ou no horário de almoço, de acordo com a disponibilidade dos mesmos. A coleta foi previamente autorizada pela delegada responsável e os funcionários mostraram-se bastante à vontade para responder às questões. As respostas foram anotadas manualmente.

Antes do início das entrevistas, os participantes foram novamente esclarecidos sobre os objetivos da pesquisa e sobre a livre participação na mesma. O sigilo sobre suas identidades e a desistência da participação na pesquisa no momento em que desejassem, como consta na regulamentação do código de Diretrizes e Normas Regulamentadoras de Pesquisas Envolvendo Seres Humanos do Conselho Nacional de Saúde, Resolução no 196/1996, também foram devidamente esclarecidos. Porque a equipe é pequena e visando a preservação da identidade dos funcionários, garantida no Termo de Consentimento Informado, identificamos os relatos transcritos ao longo deste estudo por meio da numeração dos participantes (de P1 a P14).

\section{Observações}

As observações foram realizadas ao longo de um semestre, uma vez que se revezavam com as entrevistas com os profissionais e também com a coleta de dados de BOs, realizadas para outro estudo. Assim, ao longo das coletas de dados, e sempre cuidando para não interferir na dinâmica dos serviços ali prestados, a pesquisadora pôde observar o funcionamento da Deam e a rotina de trabalho dos funcionários. Pôde-se, então, acompanhar parte dos procedimentos utilizados na Deam (recepção dos envolvidos, registro de Boletins de Ocorrência — BOs —, prisões em flagrante, depoimento de denunciados) e o modo como os profissionais lidam com as usuárias e os denunciados. Nos momentos de troca de turno, de almoço ou de intervalos entre atendimentos, foi possível também conversar com alguns dos funcionários a respeito de suas impressões sobre os serviços ali oferecidos, somando informações aos relatos já recolhidos.

\section{Organização e análise dos dados}

Os dados analisados no presente estudo referem-se, principalmente, às observações referentes à estrutura da Deam, à dinâmica de trabalho da equipe e às respostas coletadas na terceira parte do instrumento (Breve avaliação da Deam — pontos positivos e negativos). 


\section{Resultados}

A apresentação dos resultados está dividida em duas partes. Na primeira, são apresentados os funcionários da Deam, sua organização e demandas. Na segunda parte, apresentamos a Estrutura e os Recursos Físicos da Deam-Vitória.

Vale lembrar que, no período da pesquisa, a delegacia em análise era a única instalada na capital Vitória (ES) e registrava aproximadamente 130 boletins de ocorrência por mês. Em setembro de 2012 foi inaugurada uma segunda Deam no município, essa com plantão 24 horas, primeira Deam desse tipo no estado do Espírito Santo.

\subsection{Equipe de funcionários da Deam}

Constituíam a equipe de funcionários da Deam: uma delegada titular, duas digitadoras (uma delas estagiária), seis investigadores (três homens e três mulheres), duas escrivãs, duas agentes de polícia e uma auxiliar de serviços gerais. Os participantes tinham de 29 a 55 anos (M $=44,65$ anos). $O$ tempo de atuação na Deam variava de um mês (auxiliar de serviços gerais) a 25 anos (ou seja, alguns atuavam ali desde a inauguração da Deam, em 1985). Alguns dos policiais já atuavam na Polícia Civil há 30 anos.

No período da coleta de dados, a Deam realizava atendimento em horário comercial (8h-18h), de segunda a sexta-feira, porém, devido ao acúmulo de trabalho, no final do primeiro semestre de 2011, a equipe da delegacia passou a realizar atendimentos até as $16 \mathrm{~h}$, para que atividades burocráticas pudessem ser desenvolvidas após esse horário. É importante ressaltar que não eram realizados plantões.

As observações realizadas e os relatos recolhidos a respeito da equipe profissional e da execução de suas funções na Deam-Vitória revelaram os seguintes aspectos característicos do trabalho realizado e do grupo em questão, como destacado a seguir (entre aspas estão trechos de relatos recolhidos nas entrevistas ou ao longo dos períodos de observação):

- Falta de funcionários ("falta de delegada adjunta pra evitar acúmulo de relatórios" [P14]; "tem que aumentar o efetivo" [P1]);

v Prejuízo nas atividades em decorrência da deficiência de funcionários ("tem coisa que não é feita, mas não é falta de trabalho dos funcionários [sic], é falta de tempo pra dar conta" [P8]);

v Bom nível de relacionamento da equipe ("equipe superunida, dinâmica e bem resolvida. Tem bastante experiência" [P7]; "a gente troca ideias sobre o que é a finalidade da delegacia (...) "todos têm vontade de ajudar a resolver o problema" [P5]);

v Necessidade de treinamento dos profissionais ("reciclagem de pessoal" [P3]; "aumentar o efetivo e treinar" [P11], "curso para todos os funcionários da Deam, pra dar um bom atendimento à vítima. E serem obrigados a fazer" [P4]);

v Necessidade de equipe psicossocial na Deam ("aqui tinha que contar com assistente social e psicóloga" [P14]; "não tem assistente social e psicóloga" [P7]). 
Presente em muitos dos relatos, a necessidade de contratação de mais funcionários (policiais e técnicos), bem como sua adequada capacitação, são pontos fortes das demandas dos profissionais. Ainda assim, questões relativas à melhoria e ampliação da estrutura física da Deam tiveram maior quantidade de citações e foram descritas com mais detalhes.

\subsection{Infraestrutura da Deam}

\section{Localização}

A delegacia está situada em região de fácil acesso, bem servida pelo sistema de transporte coletivo municipal e distante uma quadra de uma das avenidas principais da cidade. Na mesma quadra da Deam encontra-se o Departamento Médico Legal (DML), local para onde são encaminhadas as mulheres para realizar exame de corpo de delito. Também próximos à delegacia estão os demais serviços de apoio às mulheres em situação de violência instalados na cidade (11 $1^{\text {a }}$ Vara Criminal Especializada em Violência Doméstica e Familiar contra a Mulher; Centro de Atendimento a Vítimas de Violência e Discriminação [Cavvid]; Promotoria da Mulher). Havendo disponibilidade, as mulheres são conduzidas pelos próprios policiais até esses órgãos, em veículos da Deam. A Casa Abrigo, mesmo um pouco mais distante, situa-se nas imediações e é atendida pelos motoristas disponibilizados pela $11^{\underline{a}}$ Vara.

A localização da delegacia especializada é, pois, bastante conveniente e adequada ao público, sendo de fácil acesso e permitindo um deslocamento rápido até os demais serviços de atendimento que atuam juntamente com a Deam.

\section{Estrutura e recursos físicos}

De acordo com Nader (2010), a Deam-Vitória funcionou até o ano de 2002 em uma sala da Superintendência da Polícia Civil do Espírito Santo. Em 2002 a delegacia foi transferida para uma casa adquirida pelo Governo do Estado, ao lado da Polícia Civil, onde funciona até os dias de hoje.

A Deam está instalada em uma casa antiga, com muro baixo e um pequeno jardim na frente. Na entrada, há uma varanda também pequena, com um banco estofado. A casa possui oito cômodos: sala de recepção/espera (com televisor, filtro de água, um banco, mesa e uma impressora/copiadora), sala da delegada, sala para registro das denúncias das mulheres, duas salas para registro de depoimentos dos denunciados, expedição de Pedidos de Medidas Protetivas de Urgência e abertura de inquéritos, uma antessala (área de transição para a cozinha) também utilizada para serviços burocráticos e de registro. Há ainda uma cozinha e um banheiro, ambos de uso exclusivo para os funcionários. O banheiro para as usuárias e usuários do serviço fica fora do prédio; ao lado da casa há um terreno de terra batida, utilizado como estacionamento pelos funcionários. 
Os arquivos de denúncias estão organizados por mês e ano e distribuídos em estantes por praticamente toda a delegacia, inclusive banheiro e cozinha, com exceção da recepção. As salas de atendimentos (da delegada, das digitadoras e das escrivãs) estão providas de arcondicionado, computador, mesas, cadeiras e armários. No total, são seis computadores e uma impressora, instalada em rede. A Deam é servida por um sistema de intranet de baixa velocidade.

Entre os pontos destacados pelos funcionários a respeito da estrutura e do funcionamento da delegacia estão:

จ Estrutura física precária (“delegacia é pequena, tem pouco espaço” [P8]; “a estrutura é péssima" [P2]);

- Atendimento prejudicado pela estrutura deficitária ("falta sala, falta recepção, sala pra criança, sala separada pra mulher e pro homem, pra funcionários" [P14]; "muito barulho, falta espaço e privacidade" [P6]);

v Precariedade de equipamentos e recursos materiais ("falta material, viatura" [P1]; "e tem carro parado também [quebrado] enquanto estamos cheios de ocorrências" [P10], "faltam recursos físicos e humanos" [P10], "[pontos negativos] condições de trabalho: viaturas, computadores, intranet" [P11]);

จ Organização da equipe dentro das possibilidades existentes para realização do trabalho ("dentro do que a gente tem a gente tá bem demais" [P11]; "o atendimento é bom, mas poderia melhorar se tivesse um bom espaço físico” [P9]);

v Utilização de recursos próprios para atender às demandas internas e externas ("a equipe [...] usa recursos próprios pra dar conta do trabalho [...], usa computadores próprios" [P11]; "precisavam providenciar [vale] transporte e alimentação para as mulheres atendidas, quem faz isso são os funcionários, não é a Deam que paga" [P1]).

Importante destacar que, ao longo das ações de observação, foi notável o impacto da estrutura precária da delegacia: falta de privacidade dos atendimentos realizados, ausência de salas separadas para as crianças que acompanhavam suas mães, dificuldade de algumas mulheres em serem atendidas ao entrarem na Deam (não havia atendente, a recepção dos casos era realizada pela policial que estava disponível a cada momento). Alguns casos de flagrante em que a mulher e o acusado de agressão compartilhavam o mesmo espaço da Deam enquanto aguardavam os encaminhamentos foram também observados.

\section{Discussão dos resultados}

Optamos por dividir a discussão com base na descrição utilizada para os resultados (Equipe de funcionários da Deam e Estrutura e Recursos Físicos da Deam-Vitória). 


\subsection{Equipe de funcionários da Deam}

De acordo com a Norma Técnica (Ministério da Justiça, 2010), uma cidade do porte de Vitória (população de 297.489 habitantes, segundo dados do IBGE, 2010) deveria contar com 2 Deams. A Norma Técnica ainda recomenda que o quadro de pessoal ideal para ser distribuído em cada Deam deveria ser composto por: três delegadas, 21 agentes policiais (escrivão e/ou investigadores), dois funcionários para apoio administrativo e um para serviços gerais.

Ao nos basearmos nas indicações da Norma Técnica, notamos que a Deam em questão, no período em que foi desenvolvida a pesquisa, atendia a uma demanda quase quatro vezes maior do que a prevista, posto que atuava com aproximadamente metade do quadro de pessoal sugerido (contava com 14 funcionários) e era a única em um município que já deveria contar com duas delegacias. Além do acúmulo de trabalho e dificuldade em cumprir prazos, outro impacto negativo da reduzida equipe de trabalho é o horário de funcionamento da Deam. De acordo com informação da delegada titular, o funcionamento do serviço por 24 horas e nos finais de semana, como sugere a Norma Técnica (Ministério da Justiça, 2010), era impraticável dadas as condições da delegacia.

Vale destacar que essa precária situação não é exclusividade de Vitória. O número de delegacias especializadas em todas as capitais dos estados do Sudeste também é inadequado, considerando-se o tamanho da população. No Rio de Janeiro (população: 5.940.224) há três delegacias, cada qual com uma delegada titular, todas funcionando 24 horas; em Belo Horizonte (2.258.096 habitantes), há apenas uma delegacia, servida por uma delegada titular e 11 delegadas plantonistas, e em São Paulo (população: 10.659.386) foram contabilizadas nove Deams, uma delas 24 horas. Cada delegacia paulistana conta com uma delegada titular, oito delegadas plantonistas e três adjuntas também atuam nesses serviços, num total de 20 delegadas (Observe, 2010; IBGE, 2010).

Apesar do déficit de pessoal e do acúmulo de trabalho, as observações realizadas na Deam e os relatos dos profissionais revelaram que o grupo atua no sentido de se manter integrado e executar suas funções da melhor maneira possível. Em suas entrevistas, os profissionais da Deam destacaram como os principais pontos positivos da delegacia: a equipe, o trabalho ali realizado e o bom entrosamento do grupo. Além da relação profissional, observamos também boas relações pessoais entre os entrevistados: "as pessoas são legais aqui" [P2]; "aqui é família, união de colegas" [P10]. Os almoços realizados na própria Deam (a pesquisadora participou de alguns deles), preparados pelos funcionários com alimentos levados por todos, são representativos do sentimento de grupo presente na equipe.

Além da necessidade de "mais pessoal" para atuar na delegacia, houve relatos também requisitando capacitação profissional, questão destacada por estudiosos e profissionais como importante para se oferecer serviço de qualidade às mulheres atendidas (Almeida, 2007; Blay, 2003; Guimarães et al., 2011; Santos, 2008; Silva, 2012).

As demandas por treinamento/capacitação feitas por alguns dos funcionários revelam não haver investimento em cursos que objetivem a melhor formação da equipe para o atendimento na Deam (Almeida, 2007; Blay, 2003; Santos, 2010). Essa questão é lembrada por 
Gandoni-Costa, Zucatti e Dell'Aglio (2011:226), que ressaltam que "o número de delegacias especializadas no Brasil aumentou, mas a formação de profissionais para atuação na área ainda é escassa e necessita de investimentos". Esse déficit pode resultar, em alguns casos, em atendimentos que violam outros direitos das usuárias, quais sejam os direitos por um atendimento adequado, qualificado e respeitoso.

Ao se considerar a capacitação dos funcionários e a necessidade de orientação das usuárias das Deams, amplia-se a perspectiva de ação contra a violência, uma vez que, além da criminalização do fenômeno, ganha importância o cuidado humanizado com os envolvidos (denunciantes, denunciados, familiares) para que os mesmos não sofram novas violências dentro do sistema criado para protegê-los (Guimarães et al., 2011; Silva, 2012; Observe, 2010). Em seu estudo, Silva (2012:150) afirma que a "valorização da função policial educativa, preventiva e investigativa' foi a solução que recebeu maior número de adesões por parte das delegadas enquanto procedimento muito importante para resolução dos problemas pelos quais passam as Deams".

A questão educativa e de orientação, porém, recebe precária atenção da mídia e do Estado, o que implica pouco ou nenhum investimento financeiro voltado para ações, espaços e profissionais que tratem desses aspectos. Resta à Deam, órgão de referência para o combate da violência contra a mulher, para o Estado e para a população em geral, o acúmulo de demandas advindas de usuárias que ora intentam denunciar e criminalizar seu parceiro ou exparceiro, ora requisitam informações judiciárias, orientações legais e assistência psicossocial.

Outro aspecto que viabilizaria o melhor atendimento das mulheres é, de acordo com os profissionais, a contratação de técnicos (principalmente psicólogos e assistentes sociais) para a equipe da delegacia, demanda exposta também por delegadas de outras Deams no Brasil (Observe, 2010). Um dos participantes lembrou que a criação dessa equipe na Deam, "com assistente social e psicóloga", está "prevista na Lei Maria da Penha" [P12]. Na verdade, tal condição está descrita no art. 11 do Decreto no 2.170-N (1985), que cria a Deam, mas tanto a Lei Maria da Penha como também a Norma Técnica especificam que esses profissionais devem integrar equipes multidisciplinares e serem alocados não na Deam, mas em outros espaços que compõem a rede de assistência (nos Juizados de Violência Doméstica e Familiar contra a Mulher ou Centros de Referência, por exemplo).

A Norma Técnica sugere que a Deam, por integrar uma rede de serviços, atue como porta de entrada para os serviços de atendimento, devendo indicar e mesmo acompanhar as usuárias até os mesmos. Essa rede, quando completa, deve oferecer os seguintes serviços: orientação jurídica, assistência psicossocial, proteção da integridade física, repressão/criminalização da violência, campanhas educativas sobre violência de gênero, entre outros (Ministério da Justiça, 2010).

Ainda que em desacordo com leis e normas atuais, a demanda dos profissionais da Deam está em consonância com o decreto de criação da Deam e resulta de uma verificação empírica dos profissionais, partilhada por outras equipes que atuam em Deams. Segundo o relatório Observe (2010:44), diversas delegacias do país já contam com "dependências para atendimento multidisciplinar: salas para orientação psicológica, orientação social e assessoria jurídica”. Infelizmente, não encontramos no relatório informações a respeito do tipo de ser- 
viço prestado pelas profissionais das áreas de psicologia e assistência social (antes ou após a denúncia, se individual ou em grupo, objetivos e tempo de duração), embora a função a ser exercida pelos técnicos requisitados seja um ponto interessante a ser discutido.

Nossos entrevistados revelam a necessidade de profissionais que tenham habilidades para realizar o "primeiro atendimento" [P2] (ouvir a queixa, acalmar a denunciante, explicar os procedimentos da Deam) e também a "triagem dos casos" [P9], o que, segundo alguns deles, permitiria a identificação dos casos em que a representação criminal $^{4}$ em desfavor do denunciado vai ou deveria ocorrer. Segundo um dos participantes: "[deveria] ser criado um atendimento psicossocial antes de registrar as ocorrências, evitando tantos processos" [P13]). Em resposta a esta requisição por triagem, destacamos que no Decreto no $2.170-\mathrm{N}$ (1985:6), a presença desses profissionais (psicólogos e assistentes sociais) não visa um processo seletivo das denúncias adequadas à representação criminal, uma vez que o art. 11 especifica que os mesmos orientem as partes "no que se refere à reintegração ao seu meio quando necessário", o que parece ser realizado, por exemplo, no setor de Psicologia de uma Delegacia da Mulher (DM), outra denominação para as Deams, da região de Porto Alegre (Gandoni-Costa, Zucatti e Dell'Aglio, 2011).

Dentre as atividades observadas da Deam, verificamos que a recepção das usuárias pelas digitadoras que registram os BOs é, muitas vezes, o primeiro momento de acolhimento na Deam, embora elas não tenham qualquer formação especial para tanto. Apesar de a Norma Técnica (Ministério da Justiça, 2010) sugerir que o acolhimento e as orientações sejam realizados por funcionários da própria Deam, ela enfatiza também que estes sejam capacitados para isso, o que não ocorre. Outros funcionários também reconheceram que, em algumas situações: "o policial acaba sendo juiz, padre, psicólogo, assistente social... você tem que apaziguar, aconselhar" [P3]. Estas ações são, em geral, descritas como necessárias, mas não deveriam ou não poderiam ser executadas por eles (por falta de capacitação, por excesso de tarefas ou por entenderem que não é uma função policial), o que fortalece a demanda por profissionais técnicos qualificados atuando dentro da delegacia.

\subsection{Estrutura e recursos físicos da Deam-Vitória}

A facilidade de localização e acesso da Deam é um ponto bastante positivo da delegacia por facilitar a chegada de demandas espontâneas (a mulher não precisa ser levada por um policial)

\footnotetext{
${ }^{4}$ No período da coleta dos dados, os delitos enquadrados na Lei Maria da Penha eram todos considerados de Ação Penal Privada, ou seja, a denunciante precisava registrar sua intenção de representar criminalmente contra o denunciado para que o processo fosse iniciado. Ou seja, optando pela representação, instaurava-se um inquérito e o processo criminal era aberto; caso contrário, a denúncia ficava "em aberto" por seis meses, período durante o qual ela poderia voltar e representar. Após um semestre, a denúncia era arquivada. A partir de 9 de fevereiro de 2012 , O STF instituiu que o delito de lesão corporal contra a mulher passaria a ser Ação Penal Não Condicionada, ou seja, o delito pode ser denunciado por outras pessoas e o Ministério Público não precisa da representação criminal da mulher vitimada para dar prosseguimento ao processo.
} 
bem como os encaminhamentos para demais serviços da rede (DML, serviços de assistência, entre outros). Por outro lado, a observação do espaço físico da delegacia bem como os relatos coletados permitem verificar a inadequação de sua estrutura e das condições de trabalho dos funcionários para a recepção das pessoas que ali chegam para serem atendidas.

Segundo os entrevistados, os prejuízos da infraestrutura ruim recaem tanto sobre o trabalho interno, como também sobre o atendimento às usuárias: "falta de espaço físico adequado pra atender, orientar a vítima sobre dúvidas que a mesma quer solucionar" [P4].

Nos dados do relatório Observe (2010), verificamos que, dentre as 40 delegadas entrevistadas, 10 (25\% do total) mencionaram problemas com as instalações físicas, como falta de isolamento acústico e de salas.

Entre os impactos do espaço físico precário, pudemos presenciar: o desconforto na pequena sala de espera que, em casos de flagrante, é compartilhada entre denunciante e denunciado (e também crianças e testemunhas, conforme o caso), o barulho de conversas paralelas (ora sobre o trabalho, ora não), a falta de privacidade para a mulher relatar a queixa, ou para o homem prestar seu depoimento (as salas, em geral, ficam com as portas abertas) e a ausência de salas para acomodar adequadamente todos os profissionais da equipe. Apesar de algumas dessas situações não poderem ser evitadas devido à organização espacial da Deam, avaliamos que algumas delas poderiam ser amenizadas por ações simples, como o isolamento acústico da sala das digitadoras e das escrivãs por meio do fechamento da porta de acesso e da sinalização do atendimento em curso. ${ }^{5}$

Além do espaço físico, muitos funcionários descreveram que os equipamentos e materiais de trabalho são também deficitários. Problemas com a infraestrutura são descritos também no relatório Observe (2010), que indica que 13 delegadas (32,5\%) destacam a falta de equipamentos e/ou sua precariedade (computadores, viaturas e armamentos) como o principal problema que enfrentam para realizar o trabalho em melhores condições. Essas carências podem desestimular profissionais que "vivenciam na falta de condições materiais para a realização de suas atividades, um reflexo do desprestígio que estas delegacias ainda gozam no interior das polícias" (Observe, 2010:36).

De fato, todos os profissionais demonstraram certo descontentamento com as condições de trabalho ao longo dos períodos de observação e o descaso da Polícia Civil em relação à Deam também foi descrito: “a verdade é que a delegacia (Deam) não é prioridade pra Polícia [Civil]" [P9]. Vemos pois que, para os profissionais, a atual situação da delegacia é reflexo do que denominaram "falta de vontade política" [P3] e do fato de a mesma não ser prioridade na Polícia Civil, constatações que apoiam o argumento de que a subvalorização das Deams ocorre desde a sua criação (Santos, 2008).

Ainda assim, é notável o empenho da equipe em fazer o trabalho dar certo. Segundo as observações e as entrevistas, na Deam o bom entrosamento da equipe e a dedicação ao tra-

\footnotetext{
${ }^{5}$ Ressaltamos que durante certo período mantinha-se a porta aberta para manter a ventilação adequada da sala, pois o ar-condicionado não estava funcionando. Tal artifício manteve-se, porém, mesmo estando o ar-condicionado novamente em uso.
} 
balho parecem permitir a adaptação (ao menos parcial) dos funcionários às condições dadas: compartilham salas, aguardam expedições de mandatos ou documentações na cozinha, na garagem ou em sala de colega (que às vezes está atendendo) e, em caso de pequenos consertos, os executam por conta própria. Também a utilização de equipamentos (notebooks) e de recursos próprios (comprando alimentos ou pagando passes de ônibus para mulheres atendidas) revelam os esforços para a realização das funções em um espaço de trabalho precário. Como resumiu um dos participantes ao avaliar as condições ofertadas e o que é executado pela equipe: "Dentro do que a gente tem aqui, a gente tá bem demais" [P11].

\section{Considerações finais}

Realizamos neste estudo a apresentação e análise gerais das condições de funcionamento da Deam-Vitória, com base em dados sobre seus funcionários e sua infraestrutura. A análise comparativa dos dados coletados com as propostas da Norma Técnica (Ministério da Justiça, 2010) e com as informações do relatório Observe (2010) possibilitou uma avaliação crítica acerca das condições de funcionamento da Deam-Vitória, delegacia cujos dados não haviam sido alcançados pelo relatório supracitado.

Os resultados encontrados revelam uma Deam inadequada no que diz respeito aos recursos físicos e humanos (faltam salas adequadas, funcionários e investimentos em infraestrutura e capacitação) e funcionários que se sentem pouco valorizados pelo Estado e se organizam para solucionar questões estruturais com recursos próprios, trabalhando dentro das condições que conseguem criar. Importante destacar que as demandas da equipe são, em sua maioria, condizentes com as propostas contidas tanto na Lei Maria da Penha como na Norma Técnica, e que as atribuições e o recebimento de investimentos na Deam dependem de decisões do governo estadual sobre as políticas de segurança pública (Observe, 2010), situação que nos remete à relevância da constante fiscalização e divulgação da situação das Deams em todo o país.

O presente artigo abre espaço também para uma questão importante: de que forma tornar a Deam, como previsto na Lei no 11.340/2006, um espaço não apenas de repressão, mas também de prevenção de violências quando para os próprios profissionais o trabalho de educar, ouvir e orientar parece ser uma atividade "extra"?

Se a prevenção deve estar presente nesse serviço tanto como resultado da ação repressiva - que previne a repetição de situações de violência —, como também em contextos de orientações e encaminhamentos aos demais serviços da rede de apoio (Ministério Público, redes de atendimento psicossocial, Casas Abrigo), a formação continuada dos profissionais a respeito de suas funções e do próprio fenômeno da violência (contexto histórico, relações de gênero, implicações diretas e indiretas na vida das mulheres agredidas) parece essencial.

Já em 2003, Blay destacava a importância do treinamento do efetivo das Deams, afirmando que "as Delegacias pouco podem fazer se não estiverem inseridas em um programa de transformação da cultura da força e da violência de gênero" (Blay, 2003:97, grifos nossos). 
Dada a demanda por capacitações e treinamentos, vemos, pois, que há abertura dos profissionais para iniciativas que possam incluir questões referentes à humanização do trabalho policial e ao trabalho em rede na Deam.

A promulgação da Lei Maria de Penha, em 2006, possibilitou às Deams certo destaque na mídia e um acompanhamento mais atento de seu funcionamento tanto pela população como também por pesquisadores e profissionais de diversas áreas (Saúde, Segurança Pública, Assistência Social), o que é bastante positivo. Assim, temos como de grande relevância o acompanhamento contínuo do funcionamento dos diversos serviços que compõem a rede de enfrentamento da violência contra a mulher, na qual se inserem as Deams, a fim de se manter estes espaços em destaque e, com isso, tornar públicas demandas por melhorias, divulgar sucessos/iniciativas e propiciar subsídios para o aprimoramento desses serviços.

\section{Referências}

AGENDE (Ações em Gênero, Cidadania e Direitos). 10 anos da adoção da Convenção Interamericana para Prevenir, Punir e Erradicar a Violência contra a Mulher, Convenção de Belém do Pará. Brasília: Agende Ações em Gênero Cidadania e Desenvolvimento, 2004. 36 p. Disponível em: <www.Agende. org.br/docs/File/publicacoes/publicacoes/revista\%20Convencao\%20Belem\%20do\%20Para.pdf>. Acesso em: 28 set. 2011.

ALENCAR, Daniele M.; MELLO, Marília M. P. A Lei Maria da Penha e sua aplicação na cidade de Recife: uma análise crítica do perfil do "agressor" nos casos que chegam ao Juizado da mulher (anos 2007-2008). Sociais e Humanas, Santa Maria, v. 24, n. 2, p. 9-21, jul./dez. 2011.

ALMEIDA, Suely S. Essa violência mal-dita. In: ALMEIDA, Suely S. (Org.). Violência de gênero e políticas públicas. Rio de Janeiro: Ed. UERJ, 2007. p. 23-41.

ARRUDA DA SILVA, Priscila et al. Violência contra a mulher no âmbito familiar: estudo teórico sobre a questão de gênero. Enfermería Global, v. 11, n. 2, p. 251-258, 2012.

BLAY, Eva A. Violência contra a mulher e políticas públicas. Estudos Avançados, v. 17, n. 49, p. 87-98, set./dez. 2003.

CORTEZ, Mirian B. Maridos dominadores, esposas (in)subordinadas: as implicações do empoderamento feminino e da masculinidade hegemônica na violência conjugal. Dissertação (mestrado) — Programa de Pós-Graduação em Psicologia, Universidade Federal do Espírito Santo, Vitória, 2006.

DECRETO no 2.170-N (24 de outubro de 1985). Cria a Delegacia Especializada de Defesa da Mulher. Diário Oficial, Vitória, 1985.

GANDONI-COSTA, Lila M.; ZUCATTI, Ana P. N.; DELL'AGLIO, Débora D. Violência contra a mulher: levantamento dos casos atendidos no setor de psicologia de uma delegacia para a mulher. Estudos de Psicologia, v. 28, n. 2, p. 219-227, abr./jun. 2011.

GIL, Antonio C. Como elaborar projetos de pesquisa. 4. ed. São Paulo: Atlas, 2009. 
GUIMARAES, Arleth R. C. et al. Serviço de atendimento especializado a mulheres em situação de violência no Pará. Rev. Nufen, São Paulo, v. 3, n. 2, p. 25-38, 2011.

IBGE. Censo 2010. Disponível em: <www.censo2010.IBGE.gov.br/dados/index.php?uf=33> Acesso em: 25 set. 2011.

INSTITUTO JONES DOS SANTOS NEVES. Violência contra a mulher 2008: ocorrências registradas na delegacia especializada da mulher (DEAM),Vitória-ES 2004 a 2006. Vitória, 2008. Relatório técnico. Disponível em: <www.ijsn.es.gov.br/attachments/222_ViolenciacontraMulher.pdf>. Acesso em: 15 ago. 2011.

LAMOGLIA, Cláudia V. A.; MINAYO, Maria C. S. Violência conjugal, um problema social e de saúde pública: estudo em uma delegacia do interior do estado do Rio de Janeiro. Ciência e Saúde Coletiva, v. 14, n. 2, p. 593-604, mar./abr. 2009.

MACHADO, Lia Z. Atender vítimas, criminalizar violências. Dilemas das delegacias da mulher. Série Antropologia, n. 319, 2002. Disponível em: < http://vsites.unb.br/ics/dan/Serie319empdf.pdf > . Acesso em: 7 fev. 2011.

MINISTÉRIO DA JUSTIÇA. Norma técnica de padronização das delegacias especializadas de atendimento às mulheres - 25 anos de conquistas — Deams. Brasília: Ministério da Justiça, Secretaria de Políticas para as Mulheres, 2010.

MISTRETTA, Daniele. Lei Maria da Penha: por que ela ainda não é suficiente? Revista do Laboratório de Estudos da Violência da Unesp/Marília, n. 8, p. 1-8, dez. 2011.

NADER, Maria B. Mapeamento e perfil sociodemográfico dos agressores e das mulheres que procuram a delegacia especializada em atendimento à mulher Vitória (ES). 2003-2005. In: SEMINÁRIO INTERNACIONAL FAZENDO GÊNERO 9 DIÁSPORAS, DIVERSIDADES, DESLOCAMENTOS, 2010, Florianópolis. Anais Eletrônicos... Florianópolis: UFSC, 2010. Disponível em: <www.fazendogenero.ufsc.br/9/resources/anais/1278008189_ARQUIVO_TrabalhoprontoparapublicacaoFG9.pdf > . Acesso em: 7 ago. 2011.

NUNES, Maria T.; HITA, Maria G. Violência doméstica contra a mulher e o acesso à justiça: (in) constitucionalidade da Lei Maria da Penha? In: SEMINÁRIO INTERNACIONAL FAZENDO GÊNERO 9 DIÁSPORAS, DIVERSIDADES, DESLOCAMENTOS, 2010. Florianópolis. Anais Eletrônicos... Florianópolis: UFSC, 2010 Disponível em: <www.fazendogenero.ufsc.br/9/resources/anais/1278300632 ARQUIVO_TEXTO-FAZENDOGENERO.pdf>. Acesso em: 5 abr. 2012.

OBSERVE. Observatório da Lei Maria da Penha. Condições para aplicação da Lei 11.340/2006 (Lei Maria da Penha) nas Delegacias Especializadas de Atendimento à Mulher (Deams) e nos Juizados de Violência Doméstica e Familiar nas capitais e no Distrito Federal (Relatório técnico). 2010. Disponível em: <www. Observe.ufba.br/_ARQ/Relatorio\%20apresent\%20e\%20DEAMs.pdf>. Acesso em: 10 ago. 2011.

OLIVEIRA, Marcela B. Da Delegacia de Defesa da Mulher ao Juizado Especial Criminal: significados da violência de gênero no fluxo processual. In: DEBERT, Guita G.; GREGORI, Maria F.; OLIVEIRA, Marcella B. de (Org.). Gênero, família e gerações: Juizado Especial Criminal e Tribunal do Júri. Campinas: Pagu/Núcleo de Estudos de Gênero da Unicamp, 2008. p. 15-49. 
PASINATO, Wânia. Lei Maria da Penha - novas abordagens sobre velhas propostas. Onde avançamos? Civitas, Porto Alegre, v. 10, n. 2, p. 216-232, maio/ago. 2010.

PASINATO, Wânia; SANTOS, Cecília M. Mapeamento das Delegacias da Mulher no Brasil. Núcleo de Estudos de Gênero Pagu. Campinas: Pagu/Unicamp, 2008.

ROCHA, Lourdes M. L. N. Violência de gênero e o cumprimento da Lei no Brasil: a atuação do campo jurídico. In: ALMEIDA, Suely S. (Org.). Violência de gênero e políticas públicas. Rio de Janeiro: Ed. UERJ. 2007. p. 189-212.

SANTOS, Cecília M. Da delegacia da mulher à Lei Maria da Penha: absorção/tradução de demandas feministas pelo Estado. Revista Crítica de Ciências Sociais, n. 89, p. 153-170, jun. 2010.

SANTOS, Cecília M. Da delegacia da mulher à Lei Maria da Penha: lutas feministas e políticas públicas sobre violência contra mulheres no Brasil. OFICINA DO CES: Publicação seriada do Centro de Estudos Sociais, Coimbra, 2008. Disponível em: < https://estudogeral.sib.uc.pt/bitstream/10316/11080/1/ Da\%20Delegacia\%20da\%20mulher\%20\%C3\%A0\%20Lei\%20Maria\%20da\%20Penha.pdf > . Acesso em: 15 set. 2011.

SILVA, Kelly. As Deams, as corporações policiais e a violência contra as mulheres: representações, dilemas e desafios. Rev. Bras. Segur. Pública, São Paulo, v. 6, n. 1, p. 132-154, fev./mar. 2012.

VILELLA, Wilza V.; LAGO, Tânia. Conquistas e desafios no atendimento das mulheres que sofreram violência sexual. Cad. Saúde Pública, v. 23, n. 2, p. 471-475, fev. 2007.

Lídio de Souza é doutor em psicologia. Professor do Departamento de Psicologia Social e do Desenvolvimento e do Programa de Pós-graduação em Psicologia da Universidade Federal do Espírito Santo. (in memoriam)

Mirian Beccheri Cortez é doutora em psicologia. Bolsista de pós-doutorado PNPD/Capes, do Programa de Pós-graduação em Psicologia da Universidade Federal do Espírito Santo. E-mail: mibecz@yahoo. com.br. 
